\title{
ADVANCING RESEARCH AND PRACTICE IN ENTREPRENEUR- SHIP THROUGH SPEECH ANALYSIS - FROM DESCRIPTIVE RHETORICAL TERMS TO PHONETICALLY INFORMED ACOUSTIC CHARISMA METRICS
}

\author{
NIEBUHR, Oliver*1 \\ TEGTMEIER, Silke ${ }^{2}$ \\ BREM, Alexander ${ }^{3}$ \\ ${ }^{1}$ University of Southern Denmark \\ ${ }^{2}$ University of Southern Denmark \\ ${ }^{3}$ Friedrich-Alexander-Universität Erlangen-Nürnberg
}

\begin{abstract}
Entrepreneurs aim to introduce innovations into the market, e.g., in the form of new products or services. However, innovations always mean changes, and people tend to react reluctantly to changes. Moreover, introducing innovations into the market is often linked to a higher investment risk. Thus, before ideas can become tangible reality, they first need to be "sold", for example, to supervisors, potential investors, and, finally, customers. For these reasons, it is particularly helpful for entrepreneurs to have a charismatic way of speaking with which they can persuade others of their ideas. Against this background, this paper motivates and outlines our new line of research. It focuses on charisma that emanates from the speaker's tone of voice. The line of research builds upon previous phonetic analyses of political speakers and traditional rhetorical descriptions of a speaker's charismatic tone of voice, and is meant to supplement and enrich existing verbal approaches to charisma (like the Charismatic Leadership Tactics) as well as to extend and eventually replace descriptive rhetorical terminology with an objective, acoustically-based, perceptually-informed, and technologically-supported tone-of-voice analysis, evaluation, and training. We briefly sketch our promising initial findings with regard to the quantification and training of an entrepreneur's perceived charisma. Then, we outline how our research can contribute to and get input from other fields that are more or less closely related to charisma, such as expressive speech, emotion, phonostylistics, entrepreneurship, rhetoric, and the entire field of body language.
\end{abstract}

Keywords: speech; prosody; charisma; persuasion; entrepreneurship; rhetoric.

\section{What aliens and Sudoku tell us about the research and training of charismatic speech}

At the beginning of the $21^{\text {st }}$ century, a game called Sudoku set out to conquer the world. The Sudoku hype is over today, but millions of people still play this number-placement puzzle on a daily basis (Hayes 2006). One important factor for Sudoku's success is that anyone can play it. There is no special gift, talent, or magic required - at least not from the perspective of a literate human being.

However, imagine an alien that has just arrived on Planet Earth, see Figure 1. It has never seen any numbers before, and it is familiar neither with the linear architecture of mathematics nor with the spatial arrangement of written symbols in general. In this case, a solved Sudoku puzzle would just be a visual stimulus pattern. Our alien finds this stimulus pattern appealing, fascinating, captivating, and engaging, and, therefore, thinks that the human beings who create these Sudoku patterns must be blessed with a mysterious, magic-like gift. That is, our alien is likely to feel similar to a human being who watches the alien creating a functioning QR code (see the superficial similarity between a Sudoku puzzle and a QR code in Fig.1).

Moreover, our alien would soon notice that there are millions of different Sudoku patterns that are all equally stylish and convincing. Yet as long as our poor alien knows nothing about the human language of mathematics, all the alien can do in order to create a consistent (i.e.

\footnotetext{
* = Corresponding author

Postal Address: SDU, Alsion 2, DK-6400 Sønderborg, Denmark

Phone: +49 15774753332

Web: http://findresearcher.sdu.dk:8080/portal/en/person/oniebuhr
} 
successfully solved) Sudoku pattern is to describe and memorize the patterns that it has seen before. This knowledge, however, would not help our alien be productive in the sense of creating new consistent Sudoku patterns. It would also not help our alien to be adaptive in the sense of finding proper solutions for changes in grid size or individual numbers. Furthermore, the knowledge gained from mere descriptions and the memorization of consistent Sudoku patterns would not help our alien distinguish the consistent Sudoku patterns it aims for from other non-consistent ones that it comes across.

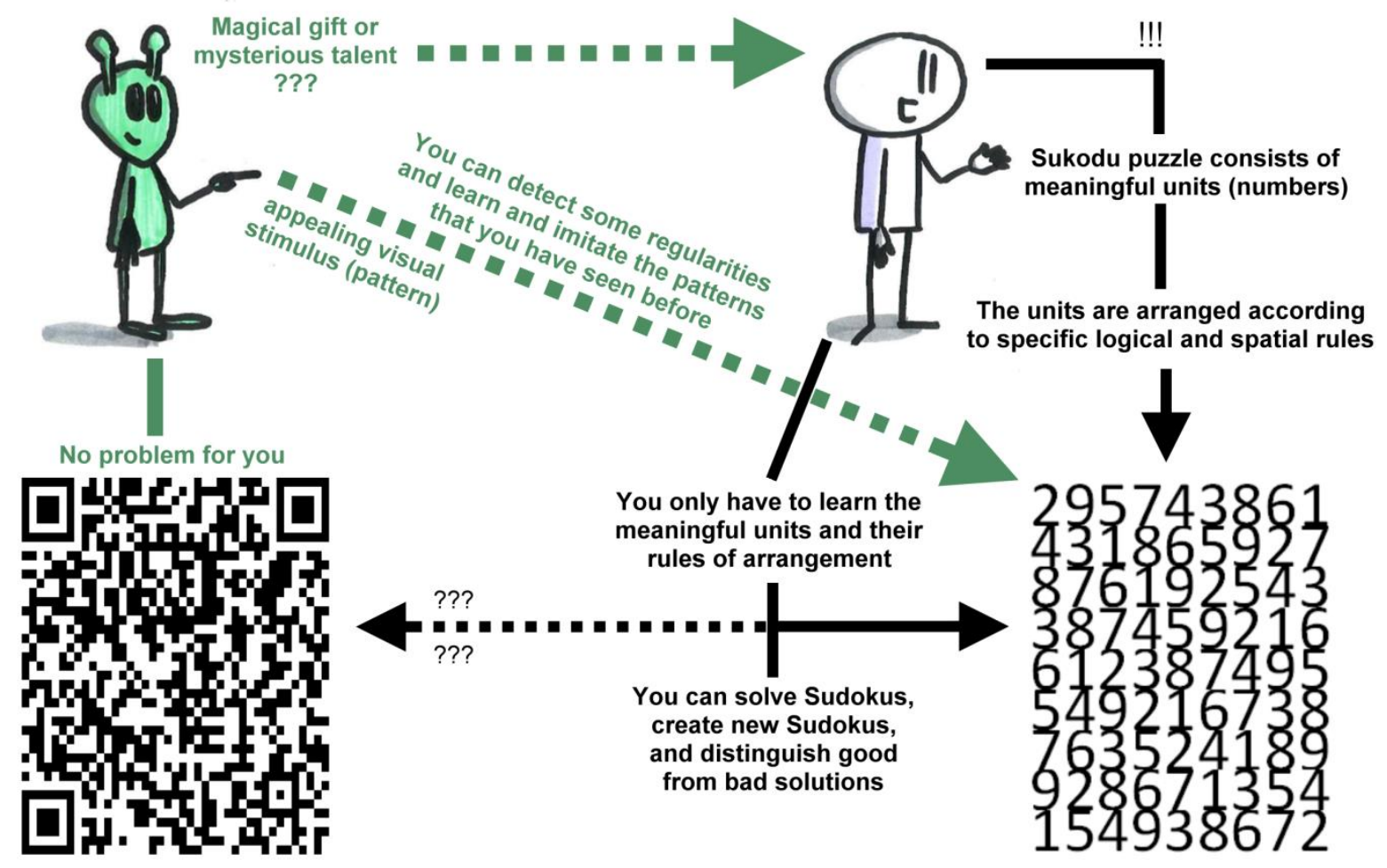

Figure 1: Sudoku analogy; drawings are made by Nathalie Schümchen.

In order to overcome these limitations and improve itself, our alien could ask a human being to teach it how to do Sudoku. Imagine if our alien did so, and if the human being told the alien that "Sudoku is based on combining straight and bent lines", that "One has to take care not to monotonously repeat a single type of line too often but should instead aim for a roughly balanced mix of the different types of lines", and that "The mix of lines should be interrupted at regular intervals by gaps that are typically smaller than the lines are long". In addition, the human being provides our alien with an inventory of consistent Sudoku patterns that it can use for learning and imitation.

If you were our alien, would you find these explanations and materials helpful? Probably not, or if so, then only in the sense that the richer associative context you obtain through learning the explanations and materials makes it somewhat easier for you to memorize consistent Sudoku patterns and correctly reproduce a larger number of them. But why are the explanations and materials of limited help to you? Because they are, at most, systematic descriptions of the observable phenomena, i.e. of mere surface characteristics, plus a repertoire of examples. What you were not taught are the underlying principles according to which a basically unlimited number of these surface characteristics can be created. In other words, you were taught the general "sound" of the language of mathematics, but not the language itself.

Our alien analogy about Sudoku and the language of mathematics aimed to illustrate the following three key issues 1.1 to 1.3 that gave the impetus for launching our new line of research on acoustic charisma profiling and training with special emphasis on entrepreneurship 
and the speaker's tone of voice. By "tone of voice" we mean prosody in general and intonation in particular (see van Heuven 1994 for the term "prosody"). We will, however, primarily use the term 'tone of voice' in the following, as it is more common in other research disciplines dealing with charisma. For the same reason, we refrain from using acoustic-phonetic terms like fundamental frequency, intensity, formants, acoustic-energy distribution, spectrogram, waveform, etc. We instead adopt more impressionistic (i.e. perception-related) terms, such as pitch, loudness, and voice quality in order to keep the paper accessible to a large, interdisciplinary readership.

\subsection{People think of charismatic speakers like our alien thinks of Sudoku}

Although the question of whether other people's thoughts or actions can be influenced through communication was intensively pursued by Plato's student Aristoteles 2,500 years ago, the term charisma is still relatively recent. It was coined by the German sociologist Max Weber (1947). He defined charisma in his seminal work as "specific gifts of the body and spirit [that are] not accessible to everybody" (p.19-20). More specifically, Weber saw charisma as a god-given skill that allows a few blessed people without any formal authority to stand out from the mass and guide others by means of their speech through a period of crisis into a better life. This idea dominated research and practice for a long time and contributed a good deal to the fact that charisma became associated with terms related to mystery and magic. Later, psychologists like House (1977), Burns (1978), and Bass (1985) challenged the work of Weber and his successors from empirical and theoretical points of view. They provided evidence that charisma is not a "miraculously-given power" (Davies 1954, p. 1083). Instead, they — and many others who joined in their line of research - show that charisma is based on skills that can be measured and learned by anyone, and which need no crisis to become relevant.

Being a charismatic speaker is useful in many everyday situations. Charismatic skills can make you appear more attractive to foreigners (Friedman et al. 1988), get you more phone numbers during speed dating, or lead to more fruitful brainstorming output (Pentland 2008); they lead to better learning outcomes in students (Towler 2003); they can help you get more investors or raise more start-up funding (Davis et al. 2017); they can make you and your product or service sound more credible and likable to customers (Gélinas-Chebat et al. 1996); they make you a more effective leader (DeGroot et al. 2011); and they can help you climb higher up the career ladder or help you get more money in salary negotiations (Bodow 2002; Jacquart \& Antonakis 2015). Based on the empirical fact that anyone can learn to speak charismatically (just as anyone can learn to play Sudoku), Antonakis et al. (2016) recently redefined charisma, reducing it to "values-based, symbolic, and emotion-laden leader signaling" (p. 304), "which is expressive in its transmission of information" (p. 303). This definition stresses the major role that communication plays for charisma. It explicitly does not include the outcome of charisma, i.e. the effects charismatic speakers have on listeners, in order to avoid being tautological and to allow for the possibility that speakers are charismatic even if they have no observable effects on certain listeners.

Despite the emerging academic view of charisma as a scalar quantity that is equally applicable to all speakers, exceptionally charismatic speakers are often still praised as if they have performed some kind of magic trick, particularly in rhetorical practice. Some recent popular-science articles characterize charisma as a divine skill, and many articles or books stress within the first few sentences that charisma is nothing magic or mysterious, which is itself very telling about the associations many people still have with this term. It seems to us that these associations may, to some degree, impede an unbiased approach to charisma in research and 
practice. For example, the amount of scientific research on charisma is still relatively small compared to related topics like emotion, and we know from our own experience that many people for whom speaking or listening are key business activities often hesitate to search for and actually take courses in charismatic speech.

\subsection{A charismatic tone of voice is often analyzed and taught like our alien was taught Sudoku}

Studies investigating a speaker's charisma from the perspective of rhetoric, management, leadership, marketing, entrepreneurship or similar related fields often entirely exclude the nonverbal aspects of delivery, especially the speaker's tone of voice, and focus on the speaker's lexical or grammatical aspects instead. In the few studies in which the speaker's tone of voice is taken into account, this was done by asking listeners to rate, on a number of scaled questions, how the speaker sounds to them. There are standardized instruments for such ratings, such as the Multifactor Leadership Questionnaire (MLQ) developed by Bass (1985), the Conger \& Kanungo Scale (CKS) of charismatic leadership (Conger \& Kanungo 1989), the Charisma Questionnaire by Verčič \& Verčič (2011), and many less scientifically established questionnaires developed and used, for example, by consultancy companies. Only a few questions or scales in these standardized instruments actually refer to the speaker's tone of voice, and those that do use vague terms such as "exciting", "skillful", "powerful", "animated", "energetic", etc.

In rhetorical training, speakers are advised to support their words "by a voice which is fluent, rich, flexible, firm, sweet, durable" (Morey, 2010, p. 60 with reference to Quintilian). Other authors recommend using a "deeper" and "fuller" voice and a "clear" or "flawless" pronunciation. Studies addressing famous speakers like Walt Whitman or Steve Jobs stress the role that their "voice-tone variety" played in their success, and conclude that it is, amongst other things, critical to avoid sounding "monotonous" (Griffin, 1992; Sørensen, 2013).

Terms and instructions like those above describe the observable phenomena or surface characteristics of a charismatic tone of voice, but not the underlying principles according to which these phenomena or characteristics are produced. Thus, in the same way as our alien was taught the general "sound" of the language of mathematics but not the language itself, analyzing and training a speaker's charismatic tone of voice has also tended to rely on the general sound of non-verbal charisma, but not on the underlying language itself. The "language of non-verbal charisma" is a signaling system by which non-verbal charisma is encoded and conveyed in a comprehensible (decodable) form to perceivers - in the present paper perceivers basically means listeners. The signaling system consists of the functional elements of non-verbal charisma, specifies their defining and distinctive physical characteristics (e.g., acoustic patterns), and provides the rules of their organization and composition.

Advising speakers to aim for a constantly high voice-tone variety is the equivalent of telling our Sudoku-loving alien not to repeat a single type of line too often when drawing its Sudoku patterns. In fact, one could even say that our alien was better off, since the descriptions it received were at least relatively precise. The terminology that is used in the analysis and training of a charismatic tone of voice is comparatively vague and subjective, and neither the diversity nor the total number of these terms is clearly limited or structured by the acoustic or physiological framework of human speech production. Moreover, there is no standard or theory for how these terms should sound and be combined.

Given this, it is no surprise that terms like "voice-tone variety" and "monotonous" are sometimes interpreted very differently. For example, Griffin (1992) and Sørensen (2013) use these terms in their papers not only with reference to pitch but also to tempo. In a course on 
"Persuasive Communication and Negotiation" at the University of Southern Denmark (taught in English in spring 2017), we asked 14 business-engineering and entrepreneurship students in a free-association test what speech characteristics they would associate with the instruction to speak with a (a) "rich", (b) "flexible", and (c) "durable" (tone of) voice. Multiple answers were allowed. The answers we received are summarized in the Wordles in Figures 2(a)-(c). All three terms elicited a large range of interpretations, from temporal aspects (speak fast, no breaks, long utterances) through loudness (loud voice) and pronunciation (careful speech, hyperarticulation), to pitch (melodious, low pitch, rising or falling pitch) and voice quality (harsh voice, not breathy). In addition, the interpretations of the three terms largely overlap and often lead to similarly vague (warm, soft, strong) or even contradictory terms (e.g., both high and low for "durable").

What terms do you associate with the instruction to speak with a .... tone of voice?

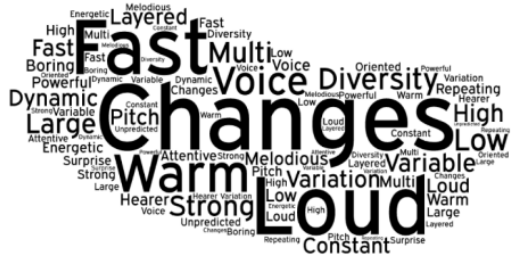

(a) $\ldots$ = rich (b) $\ldots=$ flexible

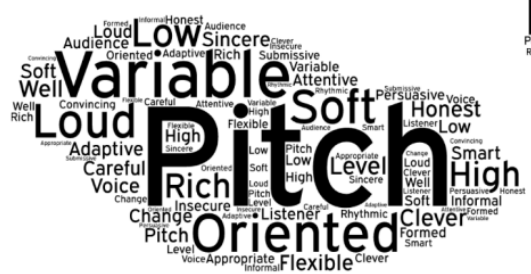

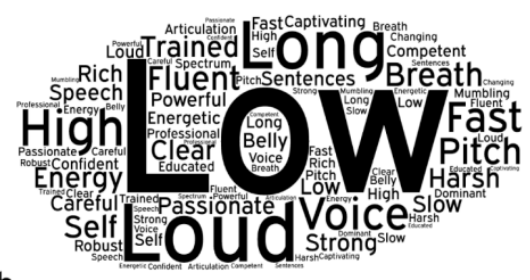

(c) $\ldots=$ durable

Figure 2: Terms spontaneously associated by 14 business-engineering and management students with the rhetorical terms (a) 'rich', (b) 'flexible', and (c) 'durable'. The associations are summarized as Wordles with larger fonts meaning shorter response times, i.e. more spontaneously given answers.

\subsection{The difference between verbal and non-verbal elements in the analysis and training of charismatic speech is like the difference between QR codes and Sudoku for our alien}

Examples like those in Figure 2 illustrate the impracticality of using existing rhetorical terms at the level of detail that would be necessary to effectively analyze, evaluate, and train a charismatic tone of voice and adapt it to different audiences and contexts. Analysis, evaluation, and training of the verbal aspects of charismatic speech are a completely different matter. Like our alien who has an easy time creating QR codes but no idea how to do Sudoku, there is a certain degree of understanding of the signaling system that underlies verbal charisma, whereas the way non-verbal charisma is handled shows that its underlying signaling system is largely uncharted territory.

This fact manifests itself in the time and space that rhetoric coaches, questionnaires, and scientific papers reserve for addressing the verbal and non-verbal aspects of charismatic speech. For example, the combination of two search items "charisma" and "verbal" yields more than three times as many hits on Google Scholar as "charisma" and "non-verbal" (about 30,000 vs. 10,000 ); and in the latter case, a good deal of papers use "non-verbal" in the sense of body movements, such as the paper by Koppensteiner \& Grammer (2010) on motion patterns in political speech and their influence on personality ratings.

The argument that we make in this paper is that work on and with charisma has so far widely "overlooked" the models and findings of acoustic and experimental phonetics (GélinasChebat et al. 1996, p. 243), which have the potential to close the knowledge gap between the verbal and non-verbal aspects of charismatic speech (see the phonetic stepping-stones in upcoming section 2.1). However, before we can close this gap, we must understand why it 
actually exists. The reason is simple. If we look at what is being said and how things should or should not be phrased, then we can base our analyses, evaluations, and trainings on three important pieces of knowledge: (1) We know that there are discrete and specific units that we can use as points of reference: the words; (2) We know that these word units have specific meanings; (3) We know how both words and meanings can be combined in speech communication. These three pieces of knowledge together allow us to select and vary wordings deliberately and to systematically compare and measure the effects of different wordings on listeners. The insights gained from such controlled comparisons, in turn, lay the foundation for providing learners of charismatic speech with clear and tangible instructions that result in reproducible outputs. For example, most of the very effective charisma-learning strategies summarized in the 12 Charismatic Leadership Tactics (CLTs) of Antonakis et al. (2011) would not exist without our knowledge about the separate units of words, their meanings, and syntactic structures. This includes analogies, rhetorical questions, contrasts, three-part lists, and metaphors. The CLTs' instructions about verbal aspects of charisma enable learners to create new, equally successful outcomes that are adapted to specific audiences, products, or situations.

A similar productive and adaptive application is lacking for the non-verbal aspects of charisma, and tone of voice in particular. In fact, the CLTs include only a single instruction about tone of voice, and this is that speakers should use an animated voice. By this, Antonakis and colleagues primarily mean a variable loudness level and the use of pauses to demonstrate control over one's line of argument (see Antonakis et al. 2012). This concept of an animated voice (sometimes also called "animated tone" or "animated voice tone", Frese et al. 2003; Towler 2003) is a further example of the problem with using vague descriptive terms. We asked the same 14 students who did the free-association task reported above what they thought characterized an animated voice. Almost all of them spontaneously associated the term with either pitch or tempo, but not with loudness, and none included pauses in their description of an animated voice.

\section{Towards researching and training the signaling system of a charismatic tone of voice}

Sections 1.1 to 1.3 above, and particularly the alien analogy, illustrate that the demystification of the term charisma is not yet fully complete, and thus, to some degree, impedes research and practice on charismatic speech. This applies in particular to the non-verbal aspects of a speaker's tone of voice, whose analysis, evaluation, and training is, unlike the supposedly more tangible verbal aspects of spoken language, still based on impressionistic descriptions of surface patterns. But is the way a speaker says something really less tangible than what s/he says? Or are we also able to identify, vary, and quantify equivalents to words, their lexical meanings, and syntax in the domain of tone of voice? In fact we are, and a considerable part of this knowledge is already available. As we stated in 1.3 , work on and with charisma has so far only widely overlooked the models and findings of acoustic and experimental phonetics and phonology. We outline in 2.1 that there are syntactically organized functional elements inside the speakers tone of voice (we call them "melodic words" here in order to stress their concreteness) that we know how to parameterize and measure in relation to meaningful categories of listeners, and that these measurements have already laid an initial empirical foundation for speaker charisma, which we can refine and extend in terms of parameters, speaker groups, and context factors.

Against this background, we believe that the time has come to take action and put the non-verbal aspects of charisma in research and practice on a new footing, which is similar or even superior to the one we already use for words. By putting the focus on the tone of voice, we take into account experimental evidence suggesting that how speakers say something is more 
important for their perceived charisma than what they actually say with words (Holladay \& Coombs 1993, 1994, see also Bies \& Shapiro 1988 and Gélinas-Chebat et al. 1996; Chebat et al. 2007). Antonakis and colleagues have argued for an objective and quantitative approach to charisma (cf. Antonakis et al. 2016). More specifically, given that most studies on charisma have thus far been based on questionnaire data, Antonakis and colleagues stress the need for "unobtrusive and objective measures" (p. 308). It is precisely these measures that will be at the heart of our approach. Our goal is to provide a description of the signaling system underlying a charismatic tone of voice and to use this signaling system for a more effective training of charismatic speech.

\subsection{The phonetic stepping-stones}

Over the last 30 years, phoneticians have developed sophisticated models of speech melody that have provided us with an inventory of "melodic words" as well as with categories of stress and emphasis to make these "melodic words" stand out in different ways in communication. We also have a set of rules for the integration and syntactic concatenation of "melodic words".

For example, Figure 3(a) shows the structure of the Kiel Intonation Model (KIM), cf. Kohler (1997), Niebuhr (2010, to appear). In this model, each prosodic phrase (i.e. a coherent section of speech in between two audible breaks) consists of three syntactic elements, a phraseinitial melody pattern (i.e. how a phrase starts), a pitch-accent melody (i.e. the melody on stressed syllables or words), and a phrase-final melody pattern (i.e. how a phrase ends). For German, three "melodic words" are distinguished phrase-initially, eight on stressed syllables or words, and six phrase-finally. When there is more than one stressed syllable or word in a phrase (which is typically the case), there is also a fourth syntactic element, the concatenation melody. It contributes to the meaning of the entire tune by the way in which it connects the two pitchaccent melodies, for example, via a high plateau or a low indentation. Furthermore, the KIM has identified nine different types of phrase boundaries whose communicative functions also differ (Peters 2006). Furthermore, there are multiple stress levels for a syllable or word that make it stand out to different degrees in perception, and approximately 14 ways to additionally emphatically highlight a syllable, word, or phrase. Altogether, the inventory of "melodic words" and their combinations and syntactic concatenations allows the KIM to identify, analyze, and distinguish between thousands of different speech melodies in the speaker's tone of voice. Of course, not all of these theoretical possibilities actually occur in conversation. Some can be excluded because the meanings of "melodic words" are incompatible; some are physically impossible to realize; and, among those melodies that do occur, some are much more frequent than others. However, similar combinatorial restrictions and frequency differences also apply to lexical items and the sentences that they can build. Although the KIM was developed for German, it is assumed that most "melodic words" also exist in other related languages such as English and Swedish, but potentially with a different meaning, cf. Kleber (2006), Ambrazaitis (2009).

Figure 3(b) shows the more widespread autosegmental-metrical (AM) model, see Pierrehumbert (1980) or Ladd (2008). Although this model differs from the KIM in many respects, its fundamental principles are similar insofar as it also distinguishes several syntactic slots within a prosodic phrase and identifies several melodic elements at each syntactic slot, the largest paradigm being associated with the pitch-accent slot (note that there is some discussion about what constitutes a "melodic word" or "intonational morpheme" in the AM model and how far forms and meanings can be decomposed into building blocks, see, for example, van Heuven 1994; Portes and Bayssade 2012, Prieto 2015; we will not go into the details of this discussion here as it is beyond the scope of the present paper). The right part of Figure 3(b) shows the 
inventory of melodic elements for (Australian) English reported in the paper by Fletcher et al. (2002).

(a)

Kiel Intonation Model (KIM)
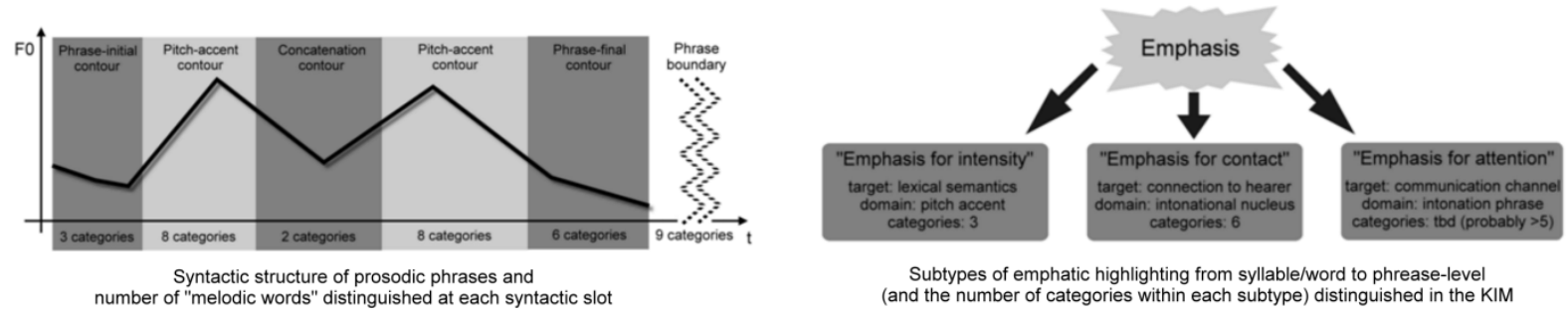

(b) Autosegmental-metrical (AM) model
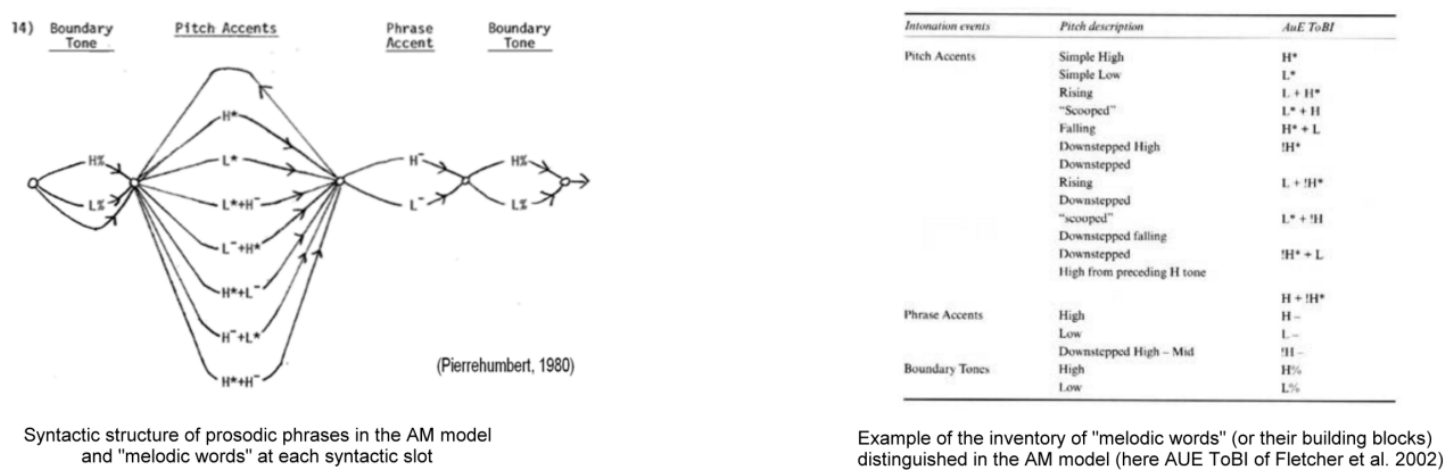

Figure 3: Representations of "melodic words", their meanings and syntactic structures in two linguistic models, the Kiel Intonation Model (a, see Niebuhr (to appear) for more information about the figures) and the autosegmental-metrical model (b).

In addition to having frameworks that define and identify "melodic words" (whose number, forms and meanings may differ between languages), we know, thanks to modern laboratory and computer-based studies, how "melodic words" and their categories of stress and emphasis can be parameterized. Moreover, more holistic characteristics of a speaker's tone of voice, such as tempo, voice quality, loudness, rhythm, pitch level, and breathing, can be reliably measured in the acoustic signal. It is also well understood how these measurements, in turn, relate to meaningful categories of listeners like emotional categories, speaker attributes, attitudes, stylistic categories, voice qualities, etc., cf., for example, Sudhoff et al. (2006), Schuller et al. (2015), and Bänziger et al. (2014).

Knowledge about meaningful functional elements and rules in a speaker's tone of voice and their relation to acoustic parameters on the one hand, and perceptual categories on the other, are crucial prerequisites for putting the non-verbal aspects of charisma (related to tone of voice) on a par with the verbal aspects of charisma. What is missing now, besides having effective tools and techniques for getting this knowledge across, is a parametric phonetic substantiation of this framework with respect to perceived speaker charisma. Also in this respect, the first stepping stones are already there.

For example, Rosenberg and Hirschberg $(2005,2009)$ analyzed the speech of nine US politicians who ran for the Democratic Party's nomination for president in 2004. Rosenberg and Hirschberg broke down the complex concept of perceived speaker charisma into a set of personality traits and identified acoustic tone-of-voice parameters that are significantly correlated with listeners' perception of speaker charisma (cf. also Bänziger et al. 2014 for a similar approach to emotions). Rosenberg and Hirschberg found that a faster speaking rate, a higher loudness level, a higher pitch level and a larger pitch standard deviation (i.e. variability) 
were positively correlated with perceived speaker charisma. A higher pitch level and a larger pitch standard deviation were also found to characterize charismatic French politicians like Jacques Chirac (Touati 1993). Touati also identified pitch range as being relevant to charisma (with a larger range being better). Later, Scherer et al. (2012), D'Errico et al. (2013), Hiroyuki and Rathcke (2016), and Bosker (2017), who investigated, amongst others, Hilary Clinton, Donald Trump, some German parliamentarians, and the Italian politician Umberto Bossi, added to the picture that shorter (and preferably silent) pauses as well as a larger (and thus less predictable) rhythmic variability, a less breathy voice, and a higher emphatic-stress frequency are beneficial for a speaker's perceived charisma. The study by Biadsy et al. (2008) additionally highlights the importance of various context factors to how effective and conducive the acoustic parameters of a speaker's tone of voice are in charisma perception. Such context factors include, for example, the listeners' familiarity with the speaker, the speaker's topic, and the cultural (and linguistic) background of the listeners, i.e. American, Palestinian, or Swedish. The latter cultural or linguistic factor, however, is put into perspective by Biadsy et al. in that they note that most of the correlations between acoustic parameters and charisma ratings were independent of "the subject's native tongue or the language rated" (p. 580).

In summary, keeping a watchful eye on cross-linguistic and cross-cultural differences, our new line of research moves on from the phonetic stepping-stones in several ways. In addition to further refining the picture of the acoustic correlates of a charismatic tone of voice, we combine these holistic measures with the existing knowledge and models of "melodic words" and, on this basis, develop rich and reliable tools and techniques for measuring, evaluating, and training a speaker's charismatic tone of voice. Being driven by tools and techniques, our approach to charisma is much more practice- and application-oriented than those of previous phonetic studies. Furthermore, previous voice tone analyses were concerned with political speakers. This is probably due to the fact the original definition of charisma by Weber (1947) requires social crises or challenges for charisma to become visible and effective. Such events often fall within the scope of politics. Weber's definition is no longer considered valid, but the focus it once put on politics is still influential. We move beyond this focus group in the direction of business people, starting with the target group of entrepreneurs.

\subsection{Why entrepreneurs?}

Basically, all kinds of professional speakers from sales agents and managers through politicians and actors to teachers and newsreaders would benefit from the research we outline in this concept paper. Yet, the group of "aliens" we decided to focus on first in our work are entrepreneurs. Firstly, this is because entrepreneurship is of increasing importance in both political debate and economic growth (van Stel et al. 2005). A number of countries, including Denmark and Germany, have special funding and support initiatives in order to foster entrepreneurship and keep their economies innovative and competitive in a world of globalized markets. Secondly, entrepreneurs are a particularly interesting (and at the same time relatively open and active) target group from the point of view of charismatic speech. They face particular and multifaceted challenges: A decisive part of their strategy and daily work is to persuade others. For example, being unknown when founding a new business, early-stage entrepreneurs need to convince external stakeholders, such as angel or venture-capital investors, customers, suppliers, municipal players and others, of their competence and the value of their ideas. In order to do so, entrepreneurs must give priority to legitimizing activities (Delmar \& Shane 2004; Hannan \& Freeman 1984; Meyer \& Rowan 1977; Fisher et al. 2017) with respect to unproven technologies, unfinished products and services, and unverified market demand (Parhankangas \& Ehrlich 2014). In addition, the probability of survival of a new business is 
significantly increased by activities that foster positive relationships with external stakeholders in the business (Stuart et al. 1999). A large portion of these activities is related to oral communication, for example, through "investor-pitching" events.

Note that "investor pitch" is a technical term in the field of entrepreneurship, in which the word "pitch" is not used in the auditory (i.e. tonal) sense, but in the sense of bringing something under discussion. According to Clark (2008), a "pitch" is an oral presentation given in front of individuals or small groups of investors/fund managers (Malmsten et al. 2002). Such presentations have a total duration of 15-30 minutes. One special subtype of "investor pitch", the so-called "elevator pitch", is typically only 2-5 minutes long. "Investor pitches" have become an important element of investors' decision-making processes, and thus, their main function is to "successfully persuade investors [...] to 'get their bums off their seats" (Clark 2008, p. 258), request a copy of the "pitch"-giver's business plan and, often after several subsequent meetings, invest money in the "pitch"-giver's entrepreneurial endeavor.

However, it is not only start-ups that need to persuade customers of their product and service offers. The same also applies to established entrepreneurs whose businesses are running well. One reason for this is that innovation is the basis of entrepreneurship and is inseparably linked with changes. People and societies are, in general, reluctant to make changes, so making progress in an entrepreneurial endeavor requires constant persuasive efforts. Furthermore, entrepreneurs are the main motivators encouraging the employees of their company to do the best work they can in order to make and keep the business successful. This applies to both types of entrepreneurs: early-stage and well-established ones.

\subsection{From acoustic charisma profiles to audience-oriented performance profiles and scores}

Figures 4(a)-(b) outline the first part of our approach. We started with analyzing multiple parameters in the acoustic signals of keynote speeches (Fig.4a) given by established entrepreneurs who are known, from either verbal analyses of charisma or statements in popularscience or newspaper articles, to be either exceptionally charismatic or not particularly charismatic. Comparing the emerging acoustic profiles of the two speaker groups (Fig. 4b) gave us an initial idea about which acoustic voice parameters are involved in conveying a charismatic impression and how much each individual parameter contributes to that impression. For example, those acoustic parameters that differ more strongly between a more and a less charismatic speaker (such as pitch range and the frequency of emphatic pitch accents/stresses in Fig. 4b) are likely to be more important for perceived speaker charisma than other parameters.

The parameter selection was also informed by existing acoustic voice tone analyses of political figures (2.1) and by the impressionistic key terms that are used in rhetorical research to describe a charismatic speaker's tone of voice (1.2). In this way, we can give traditional rhetorical terms phonetic substance. This, in turn, allows us to translate traditional rhetorical advice into more precise, objective, and quantifiable instructions for speakers. For example, inferred from the evidence we already have, the rhetorical advice to "speak fluently" can be translated into "split up your sentences into short phrases of no more than 4-5 words (about 2.02.5 seconds) and try to keep the pauses between these breaks below 500 milliseconds, i.e. the duration of about a single syllable". Our empirical evidence also suggests the need for revision of some common claims in rhetorical practice, for example, those that concern the use of a "deeper voice" and "flawless pronunciation", see 1.2. In fact (and this also is line with conclusions drawn from many political speakers, see 2.1), speakers should use a higher-pitched rather than a lower-pitched voice in order to sound more charismatic; and while a completely flawless (i.e. citation form) pronunciation bears the risk of sounding vain and less sincere, a 
moderate degree of speech reduction seems to be most suitable for a charismatic speaker (Niebuhr 2017).

We also checked whether charisma-related parameter changes found for political figures actually make business people sound more charismatic as well. This seems to be the case, at least in the qualitative sense of the direction of parameter changes. Whether a parameter change of a certain size also has the same effect for political and business speakers still needs to be determined. The well-known entrepreneurs whose acoustic profiles we have analyzed up to now include popular CEOs like Steve Jobs, Mark Zuckerberg, Elon Musk, Ginni Rometty, Meg Whitman, and Oprah Winfrey, see Niebuhr et al. (2016a,b) and Novák-Tót et al. (2017). Our analyses were based on 20-25 minutes of speech, or about 5,000 syllables and 500-700 prosodic phrases, per speaker. Figures 4(b)-(c) show data from Steve Jobs and Mark Zuckerberg that are presented in more detail in Niebuhr et al. (2016a,b).

The most notable differences between the keynote speeches of Steve Jobs and Mark Zuckerberg are that Jobs addressed his audiences at a higher pitch level and with a larger pitch range and rhythmic variability than Zuckerberg whose analyzed keynotes are characterized by frequent and long hesitations and a frequency of emphatically stressed words that is three times lower than that of Jobs. The only charisma-relevant acoustic parameter in which Zuckerberg significantly outperforms Jobs is the loudness variability in his tone of voice. Overall, these acoustic profiles are consistent with the public opinion about the two speakers. While Steve Jobs was widely considered to be "a master of the art of effective and persuasive speaking" (Paroutis et al. 2016, p.23), journalists wrote about Mark Zuckerberg that his "presentation skills are rough enough to impact Facebook's perception in a negative way" (Gruener 2011). 
Rhetorical terms and previously
identified acoustic parameters
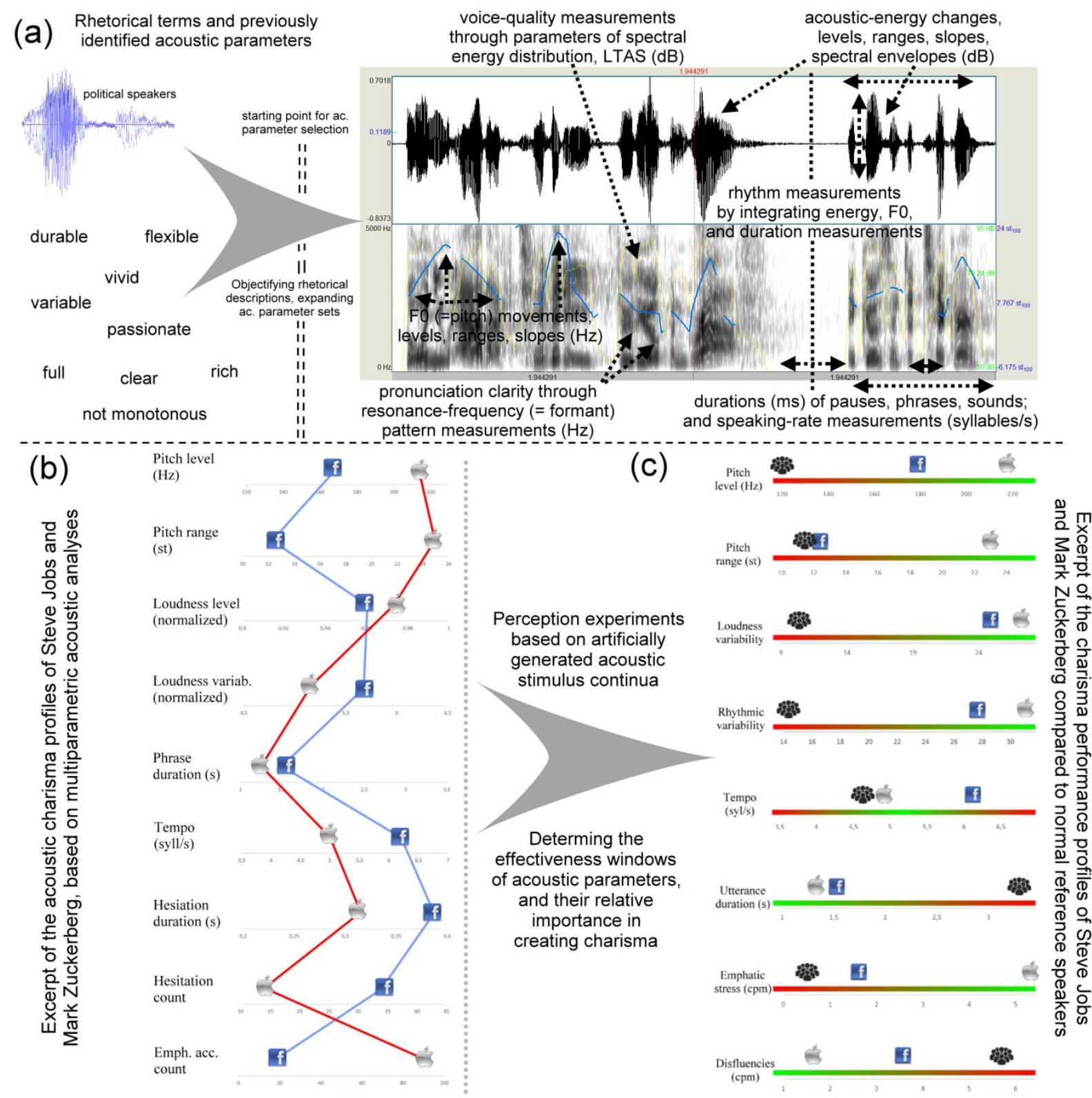

(d)

Charisma score calculation: the performance level of each parameter is multiplied

by a parameter-specific factor and then summed up. The score calculation can, e.g. be embedded in a smartphone app that offers the speakers additional feedback and training options

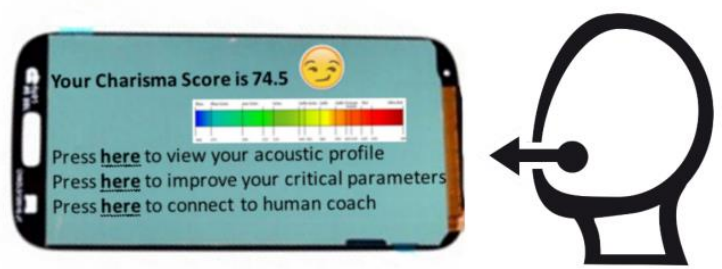

Figure 4: Outline of our paradigm shift in the analysis, evaluation, and training of a speaker's charismatic tone of voice from traditional descriptive approach of rhetoric (a) through the computer-based approach of acoustic phonetics (a, top right) and the resulting charisma profiles (b) to perception-based conversion of these acoustic profiles into performance profiles (c) and charisma scores (d) for a speaker's tone of voice. Note that (b) and (c) display results of Mark Zuckerberg and Steve Jobs, see Niebuhr et al. (2016b)

Although more internationally successful and established entrepreneurs will be analyzed in the future, we gradually shift our focus away from established entrepreneurs to early-stage entrepreneurs giving "investor pitches"; and instead of classifying speakers as more or less charismatic based on popular-science or newspaper articles, we collect metadata from the early- 
stage entrepreneurs whose "investor pitches" we record. These metadata include gender, age, linguistic and cultural backgrounds, "pitching" experience, and the type of "pitched" product or service (since new financial products, high-tech innovations, and online portals could all place different demands on a charismatic tone of voice). These basic metadata are further supplemented by scaled assessments of the "pitching" performance by the entrepreneur him/herself as well as by the audience or jury to which the "pitch" was given. The first 20 datasets (recordings and metadata) have already been gathered in this way, and a few hundred more will follow.

By shifting the focus to early-stage entrepreneurs and their "investor pitches", we address those speakers that need the most and immediate help. They cannot wait to become persuasive public speakers through experience, but need to raise funds as soon as their business idea and plan are fleshed out. On a macro or societal level, early-stage entrepreneurs who engage in fund-raising activities to receive venture capital show considerable growth potential, which makes them attractive and relevant for investors (Bygrave and Timmons 1992) and national economies alike. In fact, in modern societies, early-stage entrepreneurs have become major drivers of innovation, growth, and prosperity. By helping this target group improve their "investor pitches" with respect to the key aspect of using a charismatic tone of voice, we can conduct research with a clear-cut application perspective and a particular social and economic impact. In the other direction, as "investor pitches" are given every day and are even organized as large "pitching" events at conferences or by network initiatives of Connect Denmark (https://connectdenmark.com), quer.kraft (https://quer-kraft.org/), and E4 Impact (E4impact.org), early-stage entrepreneurs are a very rewarding source of speech data.

In overlap with the multiparametric contrastive acoustic analyses that we run on our entrepreneurial speech data, we conduct perception experiments (each with a sample of 20-30 English listeners) in which vary the acoustic parameters of test sentences in controlled equalsized steps in order to test the effectiveness ranges and levels of individual parameters and parameter bundles (Berger et al. 2017). It is reasonable to assume that too much of something can be as counterproductive for a charismatic tone of voice as too little of something, but this has never been tested in an empirical phonetic study. There must be limits up to which parameter levels can be increased; and there must be thresholds below which parameters make no significant contribution to a speaker's charismatic tone of voice.

For example, initial evidence from our perception experiments suggests that a slow speaking rate makes speakers sound less charismatic, but the same applies if the speaking rate is increased too much. Similarly, a louder voice is better, but a too-loud voice can make the speaker's perceived charisma level decrease again. A relatively low number of hesitations is beneficial for a charismatic tone of voice, but too few hesitations also reduce a speaker's perceived charisma (Fischer et al. 2017), probably because it makes their speech sound more pre-planned, and less authentic or audience-oriented. Such limits and thresholds must be determined in controlled stimulus settings, and it is likely that the effectiveness range and ideal level of each parameter also vary depending on the parametric context and the characteristics of the speaker (including his/her body language, sex, age, outer appearance etc.), the product or service the speech is about, and the size, background, and intentions of the audience.

In addition, the perception experiments we conduct at the moment will show, through the interplay of acoustic parameters, how much each individual parameter contributes to make a speaker's tone of voice sound charismatic. That is, they give us an idea of the parameters' weights in the perception of charisma. Initial evidence has already shown that (a fast) speaking rate seems to be more important for a charismatic impact than (an expanded) pitch range, which, in turn, seems to be more important than (a raised) pitch level (Berger et al. 2017). In addition, the thresholds above which parameters start making a significant contribution to a speaker's 
charismatic impact seem to be higher for female than for male speakers (Novák-Tót et al. 2017; Marlow and McAdam 2013).

Once we have determined these limits, thresholds, and weights, we can turn a speaker's acoustic charisma profile into an audience-oriented performance profile. Figure 4(c) gives an example of such a profile. The parameter-specific performance ranges are represented by a color scale from green (good/effective) to red (bad/ineffective). Speaker-individual icons (in this case representing Mark Zuckerberg and Steve Jobs) show a speaker's overall performance in terms of parameter-specific performance levels. An additional icon, the crowd (black in Fig. 4c), sets these performance levels in relation to reference values of "ordinary" speakers from the phonetic literature.

What cannot be easily repressented in graphical summaries, however, is how critical each parameter (performance) is for creating a charismatic tone of voice. Therefore, a speaker's audience-oriented performance profile will always be supplemented by a charisma score that is calculated as a weighted sum in which each performance level is multiplied by a parameterspecific factor and then summed up. Our idea here is that speakers practice their "investor pitch" (or any other kind of public speech) while talking into their mobile phone. At the end, the mobile phone displays a charisma score and gives them further options on how to proceed. These options range from presenting a list of their main weaknesses, through a giving them detailed feedback on these weaknesses, to connecting them (on the phone) to a human expert. This idea is illustrated in Figure 4(d). Note that both the audience-oriented performance profile in Figure 4(c) and the mobile-phone software calculating the speaker's charisma score in Figure 4(d) are only mock-ups, since we have only just begun to determine the perceptual limits, thresholds, and weights of acoustic charisma parameters that underlie the two speech analysis and feedback applications.

Even when the applications have been released, the performance profile and charisma scores will be continuously expanded and refined as our research on the production and perception of a charismatic tone of voice proceeds with respect to sample sizes, context factors, relevant parameters etc. This also includes integrating into the profile and score calculations which "melodic words" a speaker chose in which contexts. .

Performance profile and charisma score will not only be key metrics for research on charisma. We intend for them to become important diagnostic tools for the tailored and targeted improvement of a speaker's tone of voice. Thus, performance profile and charisma score represent the bridge between our research efforts on the one hand and our training efforts on the other. Initial results of these training efforts are briefly summarized in the following

\subsection{From research to practical application}

Regarding the training of a charismatic tone of voice, we currently investigate strategies to visualize melodic parameters in a way that is easily understandable and produces consistent realizations with speakers of different gender, backgrounds, and levels of training (see Niebuhr et al. 2017). As input for the visualizations as well as for the feedback and training that a speaker gets before and after his/her performance, we use our key research metrics (performance profiles and charisma scores, see 2.3, Figures 4c-d) as well as the phonetic models of "melodic words", stress, and emphasis categories.

A number of initial experimental studies support the success of our acoustic charisma training. We briefly summarize two of these studies below. For example, in the study summarized in Figure 5(a), 45 English-speaking participants were asked to produce a given English text as charismatically as possible. The text had the typical length of a short "elevator pitch". As the text itself could not be changed and body language was not taken into account, 
the participants had to improve their charisma only through their tone of voice. The 45 participants were randomly assigned to three equally large groups $(n=15)$, each of which was differently prepared for this task.

One group received neither instructions nor any kind of feedback. Thus, the speakers in this No-Feedback Group had to prepare themselves entirely on an independent basis. They had to rely on their own intuition as to how a charismatic tone of voice should sound, and they had to ensure that what they produced actually matched melodically with what they had in mind. The members of the second group watched a short YouTube video to help them prepare. As in the study of Towler (2003), the video contained explicit instructions about how a speaker's voice becomes more charismatic, based on traditional rhetorical terminology. In addition, participants of this Video-Feedback Group had the opportunity to imitate the voice patterns of the performer in the video.

The third group was our target group. This group received real-time acoustic feedback on the pitch of their voice, as well as on the speech signal's loudness level, which was indicated by the thickness of the pitch curve (we used the AMPITCH web application, see http://www.markhuckvale.com/): the pitch curve displayed on the screen became thinner when the speaker voice got softer and thicker when the speakers voice got louder. In addition, the displayed pitch curve that appeared across the screen from left to right was reset every four seconds. Based on this visualization framework, the subjects of this Acoustic-Feedback Group were instructed to make the displayed pitch curve move up and down on the screen as far as possible when speaking. To further support this instruction, adhesive tape was used to stick an upper and a lower horizontal reference line to the TV screen on which the pitch curve was displayed, and participants were asked to make their pitch curve hit or even go beyond these upper and lower reference lines as often as possible. In connection with this instruction, it was also pointed out to the speakers that moving the pitch curve up and down as far as possible on the screen did not mean speaking in a singsong voice but using a normal tone of voice, albeit with an expanded pitch range. Moreover, participants were instructed to keep the pitch curve as thick as possible, at least as thick as the adhesive tape of the screen. The final instruction the participants received was to divide the sentences such that the individual parts of the sentences were separated by short pauses of only about a syllable, and each part was finished before the pitch curve on the screen was reset. Based on these instructions and the real-time feedback, we directly and indirectly trained the participants of the Acoustic-Feedback Group to improve their charismatic tone of voice in terms of five decisive performance parameters: phrase length, pause duration, speech rate, pitch range, and loudness level.

The participants in all three groups had the same time to practice the given text alone in a quiet room (15 minutes). For each participant, two speech recordings were made under studio conditions; one before practicing and one after practicing. The recordings were analyzed both acoustically and in the form of ratings by 31 naive English-speaking listeners, who judged the speakers' performances on Likert scales in terms of attributes that Rosenberg and Hirschberg (2005, 2009) found to be strongly and consistently correlated with charisma: engaging, convincing, passionate, and charming.

Figure 5(a) shows the integrated acoustic and perceptual results in terms of the average relative improvement of a group's charismatic tone of voice in the before-and-after comparison. As can be seen, the Video-Feedback Group, who watched a charismatic speaker and received corresponding instructions based on the traditional rhetorical terminology for a speaker's tone of voice, barely improved in the before-after comparison. The Video-Feedback Group performed even worse than the No-Feedback Group, whose speakers became about $20 \%$ more charismatic after the 15 minutes of training, simply based on their own intuition. Although this is already a considerable improvement, the Acoustic-Feedback Group was still able to outperform both the 
Video-Feedback and the No-Feedback group. Based on the real-time feedback on their tone-ofvoice parameters that the Acoustic-Feedback group used for their training, the speakers were on average $41.6 \%$ more charismatic than they had been 15 minutes before (a MANOVA and an ANOVA were used to analyze the acoustic and perceptual data, respectively; all between-group differences were statistically significant at the 0.05 level).

(a)

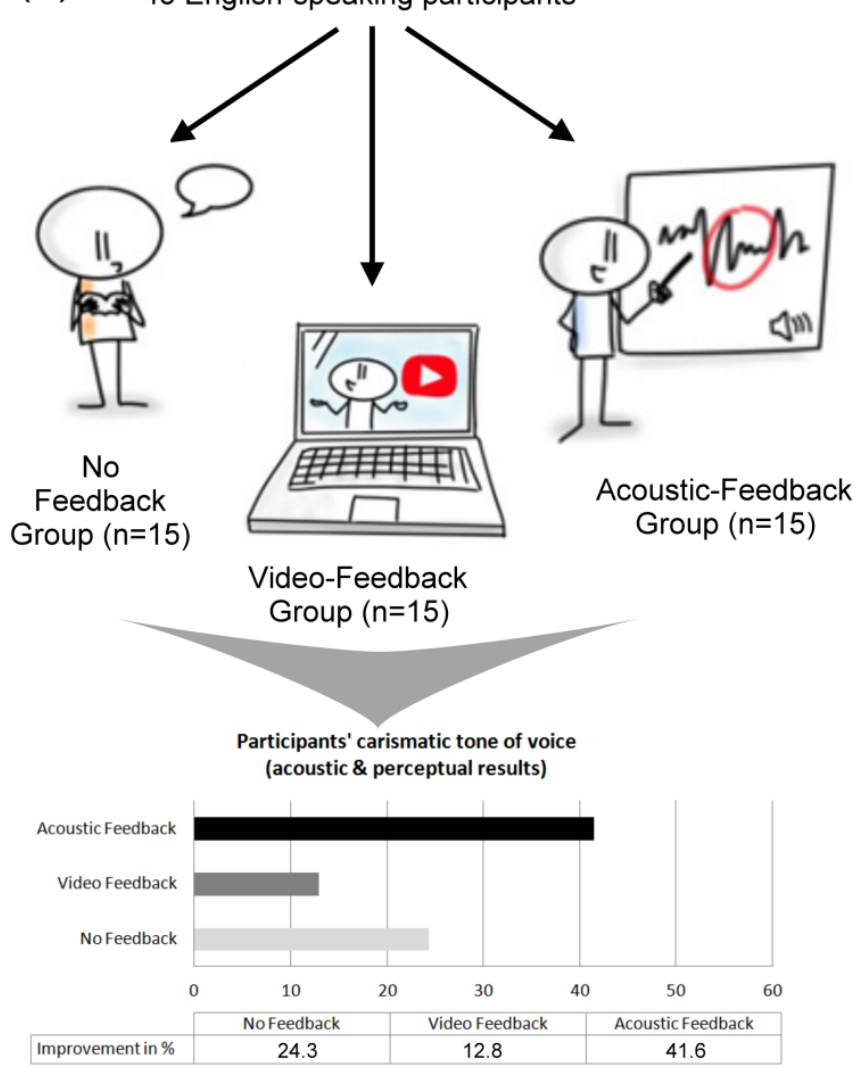

(b) 27 English-speaking participants

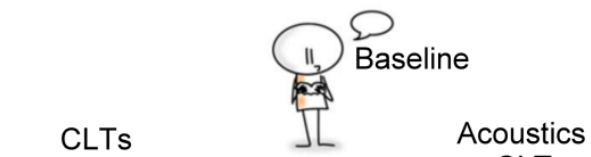
+Acoustics $(n=13)>(n=14)+C L T s$
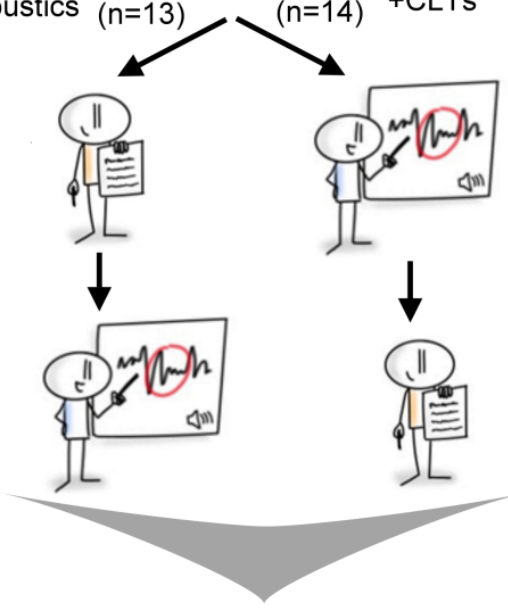

Participants' carismatic tone of voice (acoustic \& perceptual results)

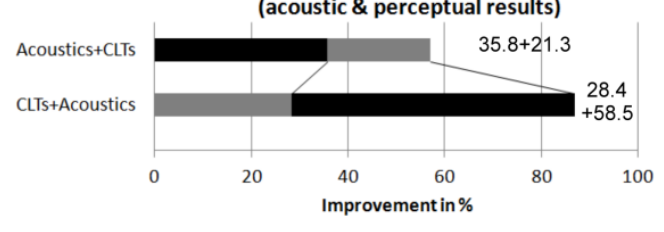

Figure 5: Sketches of the experimental designs (top) and results (bottom) of two studies conducted to evaluate the success of our acoustic charisma profiling and training of a speaker's tone of voice in relation to (a) other/no means of training and (b) an established verbal means of training (CLTs). Drawings were made by Nathalie Schümchen.

Figure 5(b) provides a summary of a further experiment carried out as a modified variant of the first experiment in Figure 5(a). This time, 27 English-speaking participants took part. The experiment consisted of three parts. In the first part, the participants received a prepared text (again of the length of an "elevator pitch") that they were asked to produce as charismatically as possible. A first realization was recorded separately for each participant in a silent room under studio conditions right after they received the text ('Baseline' condition).

In the second part of the experiment, the participants received the same text again, but this time, 13 of the 27 participants were asked to improve the verbal content of the text based on the Charismatic Leadership Tactics (CLTs) of Antonakis et al. (2011) that were handed out to them without the CLTs' rudimentary non-verbal advice. In contrast, the other 14 participants were asked to improve their charismatic tone of voice. To that end, they received the same realtime acoustic-feedback setup that was used in the experiment of Figure 5(a). Which participant was assigned to which task was random. All 27 participants were given the same time (15 minutes) for implementing or training their improvements. Then, each participant produced the text again in a second round of recording. 
In the third part of the experiment, the group that in the second part had had to improve charismatic tone of voice, now received the CLTs in order to improve the verbal content of the text; and the group that had originally received the text-oriented CLTs was now asked to improve charismatic tone of voice based on the real-time acoustic-feedback setup. Again, individual speech recordings were made after the same amount of time (15 minutes) for voice training or text improvement was given to all participants.

The results were acoustically analyzed and perceptually rated as in the other experiment; and, as in the other experiment, a MANOVA was carried out on the acoustic and an ANOVA on the perceptual data. The results are displayed in Figure 5(b) in terms of the groups' average improvement percentages across the acoustic and perceptual data in relation to the initial Baseline condition. The acoustic real-time feedback on charisma-related tone-of-voice parameters increased the charismatic performance of the speakers more strongly than the CLTs, independently of whether this text-oriented charisma improvement and training came first or last. However, there is an interesting significant interaction between the text-oriented CLTs and the voice-oriented acoustic feedback. The overall improvement of a speaker's charisma was significantly larger for those speakers who first improved the text and then their voice than for those participants who received the two charisma interventions in the reverse order. We assume that this is due to the fact that training the tone-of-voice-based acoustic feedback is easier and more effective for speakers if the text, due to application of the CLTs, contains more suitable "docking stations" for "melodic words" and emphatic highlighting. In the words of one of our reviewers: that the tone-of-voice training was more effective after the text itself was improved "highlights the importance of textual interpretation prior to the prosodic training". However, further experiments are needed to test this assumption.

Additional experiments have shown, for example, that a transfer of the acoustic-charisma profile of Steve Jobs to speaking robots increased the effects that these robots had on peoples' actions and attitudes by about $20 \%$ compared to a baseline tone-of-voice setting, see also the related work of Rodero (2017). In addition, after the 14 students of the course "Persuasive Communication and Negotation" (spring 2017, see 1.2) received our acoustic charisma training as part of their study program at SDU the willingness of potential investors to invest in their (fictional) start-up companies more than doubled compared to baseline recordings that were made at the beginning of the course. These positive findings are the driving force for us to further expand our training activities and, above all, to expand the acoustic and perceptual charisma profiling research on which the training is based.

\section{Conclusion}

In this paper, we have highlighted the fact that charismatic speech is still surrounded by myths and magic in the consciousness of many people. This is true despite the fact that charismatic speech, in all its verbal and non-verbal components, represents recognizable, definable, and thus ultimately learnable factual and procedural knowledge that is barely different from learning how to play Sudoku, except perhaps for the level of difficulty. It is possible that the persistent association of charismatic speech with myths and magic is rooted in the fact that charisma aims at our feelings and attitudes, whose physical shapes and meanings are less tangible for us than numbers on the Sudoku grid; and it is perhaps for the same reason that both research and training are much more advanced for the verbal aspects of charismatic speech - that is, for the inherently tangible, linearly ordered and combinable words and their meanings - than for the non-verbal aspects and in particular, the speaker's tone of voice. Understanding and training of the latter have not yet developed far beyond the description of surface patterns using vague, 
descriptive-impressionistic terms. This is true although tone of voice plays a greater role in the perception of charismatic speakers than the choice of words alone, and although we have, for many years already, solid phonetic stepping-stones that make the speaker's tone of voice similarly tangible and quantifiable as the speaker's words and that provide us with an initial understanding of which acoustic parameters or parameter changes are involved in perceived charisma.

At this point, our new research line of acoustic charisma profiling and training comes into play. It is designed to make the speaker's tone of voice an objective (i.e. definable) and quantifiable object that includes, in addition to holistic acoustic-prosodic characteristics, local meaningful functional elements ("melodic words") in a syntagmatic structure. We want to understand, measure, and teach how these holistic and local aspects of a speaker's tone of voice form the complex, variable, and adaptive signaling system that underlies a charismatic tone of voice. Our approach is interdisciplinary and combines the instrumental and experimental aspects of acoustics, psychology, and phonetics with data, models, and theories from management and entrepreneurship research. We have outlined above how we proceed, in a spiral-like progression, from acoustic profiles and parameter weights/hierarchies to audience-oriented performance profiles and integrated charisma scores, based on large amounts of data and sample sizes. We have additionally shown how the obtained results, in combination with an appropriate visualization strategy (which is a research subject in its own right), lead to effective training and evaluation of a charismatic tone of voice.

Although we have already achieved significant initial success in both research and training, we are without a doubt still at the beginning of our line of research. One major future challenge will be to identify and consolidate the systematic links between acoustic parameter settings and perceived charisma. This concerns individual parameters as well as parameter bundles. Another related challenge will be to shed light on the interplay between the verbal and non-verbal aspects of charismatic speech and investigate how this interplay can be optimized. Both a statement and its tone of voice consist of meaningful units. Therefore, it is reasonable to assume that, for example, some combinations of lexical and melodic words are more beneficial (or harmful) for a speaker's charisma than others. That is, we must bring together the CLTs with the phonetic-phonological models of intonation, stress, and emphasis. Over and above these specific challenges, we plan to offer a charisma training whose instruments help speakers adapt their charismatic tone of voice more effectively to different audiences (e.g. taking into account their cultural background), speaker characteristics (e.g., gender, age, and language background), products, and situations. To that end, we must first identify the contextual factors that influence the production and perception of a charismatic voice and understand their individual effects. One approach we pursue in this context, besides collecting data and metadata from enough speakers from different countries, is to create different contexts in the laboratory based on virtual-reality and acoustic-ambiance simulations. We also measure speech breathing patterns based on innovative new belt techniques. This is to better understand how breathing techniques and patterns before and while speaking change a speaker's voice quality in connection with perceived charisma, cf Apps (2009).

Ultimately, we must also take into account the numerous connections between our line of research and lines of research in other disciplines. These connections go in both directions, i.e. we provide output to other areas and get input from other areas, although the proportions of output and input may vary.

One area for which, from our perspective, the output exceeds the input is the area of emotions. Being charismatic does not simply mean speaking emotionally. On the contrary, if we put aside for the moment the complex origins, manifestations, and conceptualizations of emotions (Plutchik 1991; Scherer 2005; Bänziger et al. 2014) and understand emotions very 
generally as an environmentally-induced involuntary hybrid reaction of the body and brain that affects physiological processes and thus creates a uniform long-term imprint on speech production, then charismatic speech is not emotional in the intended sense of the term. It is expressive and shaped by emotion-like patterns whose intensity and valence vary quickly — but more often than not without any external stimulus. Not least for this reason, the emotion-like patterns in charismatic speech are typically not real. They may be superimposed on real emotions, but these real emotions are not those that are typically associated with charisma. For example, speakers are often rather nervous or anxious during presentations, but must sound cheerful, surprised, or indignant at the appropriate points of their speech. These acted emotions in charismatic speech are additionally accompanied by a multitude of verbal and non-verbal expressive linguistic elements, which are actually part of the speaker's consciously applied, planned linguistic knowledge, but often seem to be misinterpreted as involuntary emotional aspects of charismatic speech. Against this background, we believe that our research can provide useful empirical data for a better recognition, conceptualization, and (theoretical) separation of authentic and acted emotions, as well as for a clearer definition of the concept of emotion in relation to expressivity in speech communication. It is not for nothing that the charisma definition of Antonakis et al. (2016) explicitly distinguishes between emotion-loaded signaling on the one hand, and its expressive transmission on the other (see 1.1).

Another area that can benefit from our research output is the analysis of voice quality (Gerrat \& Kreiman 2001; Garnier et al. 2007; Camargo and Madureira 2008; Starr 2015). The starting point here seems to be similar to our starting point in charismatic speech. Major challenges in voice-quality analysis are the objectification of listener impressions, the standardization of descriptive terms and how they relate to one another, and the definition of proper acoustic metrics for the evaluation, training, and treatment of pathological voice qualities. Given this, it seems likely that some aspects of our approach and findings will advance voice-quality analyses and stimulate more intensive research in this area. Similarly, we are confident that our research will feed back into the large number of traditional rhetorical terms and help group, organize, and systematize these terms so that the total number of terms can be substantially reduced and their interpretation standardized.

A field of research for which input and output connections to our line of research are roughly equally strong is the area of entrepreneurship or leadership in general. Previous research in entrepreneurship has mainly focused on analyzing either the content of written business plans (Brinckmann et al. 2010) or the strategic content of performed "investor pitches", such as industry experience and the business-to-customers marketing plans. However, it is not only content that determines the decision of venture capitalists to invest in an entrepreneurial endeavor (Fang et al. 2006; Franke et al. 2004; Streletzki and Schulte 2013). The entrepreneurship community is well aware of the fact that the entrepreneur's communication skills (Brettel 2002) and the overall impression s/he makes in an oral presentation (Chen et al. 2009; Tsai and Lai 2011) are an important further factor in successfully obtaining investments. For example, Tsai and Lai defined persuasion strategies for the verbal content of a "pitch" using a qualitative approach that requires linguistic knowledge to make the oral persuasiveness factor accessible in quantitative terms. Our charisma research fills a quantification gap in entrepreneurship research and offers, on this basis, new opportunities for Tsai and Lai and others to continue their work. In addition, we offer a docking point for Zacharakis and Shepherd's work on cognitive factors in investor decisions (Zacharakis and Shepherd 2001). Furthermore, we contribute to recent research (Lucas et al., 2016) showing that investors are not consistently able to capture the entrepreneur's passion about his or her business idea through a "pitch". These and other similar studies from the entrepreneurship community also provide important guidelines for us as to which types of questions need to be addressed and which 
presentation conventions, expectations, and content structures we need to take into account in analyzing and training "investor pitches".

In the more input-oriented direction, research on the prosodic correlates of expressivity and speaking styles can enrich our line of research on the charismatic tone of voice, for example, in terms of the extent to which charismatic speech correlates with certain speakingstyle patterns and may co-vary with these patterns across different conversational contexts and situations (Perrotin and d'Alessandro 2016). We can also get ideas from this style-oriented research on which contexts and situations could be relevant. Questions as to what extent global and local pronunciation (and/or speech reduction) settings represent an integral part of the charismatic tone of voice must also be pursued in more detail (we have briefly discussed the necessity of combining the domains of sounds and prosodies in section 2.3). Such research should also involve the area of sound symbolism (Hinton et al. 1994). Whether and how a targeted use of sound symbolism (e.g., in terms of the choice of words based on their phonetic characteristics and associated meanings) is effective in charismatic speech has, to the best of our knowledge, never been tested. This possibility is also not taken into account in the verbally dominated CLTs of Antonakis et al. (2011, 2012). We consider this a fruitful option for followup studies.

Finally, there is the area of body language, which ranges from mimicry and gestures, through general body posture and tension, to the speaker's clothing and outer appearance (Furnham and Petrova 2010; Jessop 2010; Peters and Hoetjes 2017). Investigating how this aspect of a speaker's non-verbal charisma interacts with the tone of voice in terms of both the combination and the coordination of patterns (and individual cultural norms) is of major importance for our own line of research as well as for understanding and training speaker charisma in general. Therefore, we will seek interdisciplinary collaboration for a number of points of connection in our own line of research.

To conclude, Antonakis et al. (2016, p. 309) see "a very rosy future for the charisma construct". In view of how fascinatingly complex and multifaceted but still quantifiable and definable the acoustic profiles of a speaker's charismatic tone of voice seem to be, and in view of the success and societal relevance of our initial training efforts and their further enhancement by computer-based tools and techniques like virtual-reality audience simulations and smart phone apps, we very much share their enthusiasm.

\section{Acknowledgements}

The authors of this paper are very grateful to Janina Sundermeier, Meg Zellers, and three other anonymous reviewers for their constructive and insightful comments on earlier drafts of this paper. We would also like to thank Plinio Barbosa for his advice, dedication, and guidance in making the paper suitable for JoSS' new debate section. Further thanks are due to Ferran Giones, Rebecca Funken, and all participants of our workshop on the links between speech and entrepreneurship at the 7th international Leuphana Conference on Entrepreneurship (Lünenburg, Germany, 2017) for their encouraging feedback, stimulating research ideas, and helpful suggestions. Finally, we are very much indebted to Filipe Modesto for his thorough and timeconsuming typesetting work and to our committed BA students or interns Jana Voße, Eszter Novák-Tót, Jana Thumm, and Slavoljub Drobnjak for their tremendous help in collecting data and conducting experiments. 
Advancing research and practice in entrepreneur-ship through speech analysis - from descriptive rhetorical terms to phonetically informed acoustic charisma metrics

\section{REFERENCES}

1. Ambrazaitis G. Nuclear Intonation in Swedish : Evidence from Experimental-Phonetic Studies and a Comparison with German. Travaux de l'Institut de Linguistique de Lund, 49. Lund: Lund University Press; 2009.

2. Antonakis J, Fenley M, Liechti S. Can charisma be taught? Tests of two interventions. Acad. Manag. Learn. Educ. 2011;10:374-396.

3. Antonakis J, Fenley M, Liechti S. Learning charisma: Transform yourself into someone people want to follow. Harvard Bus. Rev. 2012:127-130.

4. Antonakis J, Bastardoz N, and Jacquart P. Charisma: An ill-defined and ill-measured gift. Annual Review of Organizational Psychology and Organizational Behavior 2016;3:293-319.

5. Apps J. Voice of Influence: How to get people to love to listen to you. Bethel: Crown House; 2009.

6. Bänziger T, Patel S, and Scherer KR. The Role of Perceived Voice and Speech Characteristics in Vocal Emotion Communication. Journal of Nonverbal Behaviour 2014;38:31-52.

7. Bass BM. Leadership and Performance Beyond Expectations. New York: Free Press; 1985.

8. Berger S, Niebuhr O, Peters B. Winning Over an Audience - A Perception-based Analysis of Prosodic Features of Charismatic Speech. In: Proc. 43rd Annual Meeting of the German Acoustical Society (DAGA), Kiel, Germany, 2017. 1454-1457.

9. Biadsy F, Rosenberg A, Carlson R, Hirschberg J, Strangert E. A cross-cultural comparison of American, Palestinian, and Swedish perception of charismatic speech. In: Proc. International Conference of Speech Prosody, Campinas, Brazil, 2008. 579-582.

10. Bies RJ, Shapiro DL. Voice and justification: Their influence on procedural fairness judgments. Academy of Management Journal 1988;31:676-685.

11. Bodow S. Charmed I'm sure. USA Today; 2002. URL: http://www.usatoday.com/money/jobcenter/workplace/successstrategies...

12. Bosker HR. The role of temporal amplitude modulations in the political arena: Hillary Clinton vs. Donald Trump. In: Proc. 18th Interspeech Conference, Stockholm, Sweden, 2017. 1-5.

13. Brettel M. Entscheidungskriterien von Venture Capitalists, eine empirische Analyse im internationalen Vergleich. Die Betriebswirtschaft 2002;62:305-325.

14. Brinckmann J, Grichnik D, Kapsa, D. Should entrepreneurs plan or just storm the castle? A metaanalysis on contextual factors impacting the business planning-performance relationship in small firms. Journal of Business Venturing 2010;25: 24-40.

15. Burns JM. Leadership. New York: Harper \& Row; 1978.

16. Bygrave WD, Timmons JA. Venture Capital at the Crossroads. Boston: Harvard Business School Press; 1992.

17. Camargo Z, Madureira S. Voice quality analysis from a phonetic perspective: Voice Profile Analysis Scheme (VPAS) Profile for Brazilian Portuguese. In: Proc. 4th International Conference of Speech Prosody, Campinas, Brazil, 2008. 57-60.

18. Chebat JC, El Hedhli K, Gélinas-Chebat C, Boivin, R. Voice and Persuasion in a Banking Telemarketing Context. Perceptual And Motor Skills 2007;104:419-437.

19. Chen X, Yao X, Kotha S. Entrepreneur passion and preparedness in business plan presentations: A persuasion analysis of venture capitalists' funding decisions. Academy of Management Journal 2009;52:199-214.

20. Clark C. The impact of entrepreneurs' oral 'pitch' presentation skills on business angels' initial screening investment decisions. Venture Capital 2008;10:257-279.

21. Conger JA, Kanungo RN. Charismatic leadership in organizations. Thousand Oaks: SAGE Publications; 1998.

22. Davies JC. Charisma in the 1952 campaign. Am. Polit. Sci. Rev 1954;48:1083-1102.

23. Davis BC, Hmieleski KM, Webb JW, Coombs JE. Funders' positive affective reactions to entrepreneurs' crowdfunding pitches: The influence of perceived product creativity and entrepreneurial passion. Journal of Business Venturing 2017;32:90-106.

24. DeGroot T, Aime F, Johnson SG, Kluemper D. Does talking the talk help walking the walk? An examination of the effect of vocal attractiveness in leader effectiveness. The Leadership Quarterly 2011;22:680-689.

25. Delmar F, Shane S. Legitimating first: organizing activities and the survival of new ventures Journal of Business Venturing 2004;19:385-410.

26. D'Errico F, Signorello R, Demolin D, Poggi I. The perception of charisma from voice. A crosscultural study. In: Proc. Humaine Association Conference on Affective Computing and Intelligent Interaction, Geneva, Switzerland, 2013. 552-557. 
27. Fang CM, Tsai HT, Shih MH, Chang HJ. A study on the evaluation criteria of venture capital and manager's characteristics. Journal of Entrepreneurship Research 2006;1:175-196.

28. Fischer K, Niebuhr O, Novák-Tót E, Jensen LC. Strahlt die negative Reputation von Häsitationsmarkern auf ihre Sprecher aus? In: Proc. 43rd Annual Meeting of the German Acoustical Society (DAGA), Kiel, Germany, 2017. 1450-1453.

29. Fisher G., Kuratko D, Bloodgood J.M., Hornsby J.S. Legitimate to whom? The challenge of audience diversity and new venture legitimacy. Journal of Business Venturing 2017;32:52-71.

30. Fletcher J, Stirling L, Musin I, Wales R. Intonational rises and dialog acts in the Australian English map task. Language and Speech 2002; 45:229-253.

31. Franke N, Gruber M, Henkel J, Hoisl K. Die Bewertung von Gründerteams durch Venture-CapitalGeber. Die Betriebswirtschaft 2004;64:651-670.

32. Frese M, Beimel S, Schoenborn S. Action training for charismatic leadership: two evaluations of studies of a commercial training module on inspirational communication of a vision. Pers. Psychol. 2003;56:671-697.

33. Friedman HS, Riggio RE, Casella DF. Nonverbal skill, personal charisma, and initial attraction. Personality and Social Psychology Bulletin 1988;14:203-211.

34. Furnham A, Petrova E. Body language in business - Decoding the signals. London: Palgrave; 2010.

35. Garnier M, Henrich N, Castellengo M, Sotiropoulos D, Dubois D. Characterisation of Voice Quality in Western Lyrical Singing: from Teachers' Judgements to Acoustic Descriptions. Journal of Interdisciplinary Music Studies 2007;1:62-91.

36. Gélinas-Chebat C, Chebat JC, Vaninsky A. Voice and Advertising : Effects of Intonation and Intensity of Voice on Source Credibility, Attitudes toward the Advertised Service and the Intend to Buy. Perceptual and Motor Skills 1996;83:243-262.

37. Gerratt BR, Kreiman J. Toward a taxonomy of nonmodal phonation. Journal of Phonetics 2001;29: $365-381$.

38. Griffin LD. Walt Whitman's Voice. Walt Whitman Quarterly Review 1992;9:125-133.

39. Gruener, W. On Stage, Mark Zuckerberg is no Steve Jobs. Tomsguide; 2011. URL: https://www.tomsguide.com/us/facebook-skype-video-calling-social-networking,news-11808.html

40. Hannan M, Freeman J. Structural intertia and organizational change. American Sociological Review 1984;49:149-164.

41. Hayes, B. Unwed Numbers. American Scientist 2006;94:12-15.

42. Hinton L, Nichols J, Ohala JJ, editors. Sound symbolism. Cambridge: Cambridge University Press; 1994.

43. Hiroyuki T, Rathcke T. Then, What is Charisma? The Role of Audio-visual Prosody in L1 and L2 Political Speeches. In: Proc. Phonetik \& Phonologie im deutschsprachigen Raum, Munich, Germany, 2016. 1-3.

44. Holladay SJ, Coombs WT. Communicating visions: An exploration of the role of delivery in the creation of leader charisma. Management Communication Quarterly 1993;6:405-427.

45. Holladay SJ, Coombs WT. Speaking of visions and visions being spoken an exploration of the effects of content and delivery on perceptions of leader charisma. Management Communication Quarterly 1994;8:165-189.

46. House RJ. A theory of charismatic leadership. In: JG Hunt, LL Larson, editors. The Cutting Edge. Carbondale: S. Ill. Univ. Press, 1977. 189-207.

47. Jacquart P, Antonakis J. When does charisma matter for top-level leaders? Effect of attributional ambiguity. Acad. Manag. J. 2015;58:1051-1074.

48. Jessop, EN. A gestural media framework: Tools for expressive gesture recognition and mapping in rehearsal and performance. PhD thesis, Massachusetts Institute of Technology, Boston, USA; 2010.

49. Kleber F. Form and function of falling pitch contours in English. In: Proc. 3rd International Conference of Speech Prosody, Dresden, Germany, 2006. 61-64.

50. Kohler KJ. Parametric control of prosodic variables by symbolic input in TTS synthesis. In: JPH van Santen, RW Sproat, JP Olive, J Hirschberg, editors. Progress in Speech Synthesis. New York: Springer, 1997. 459-475.

51. Koppensteiner M, Grammer K. Motion patterns in political speech and their influence on personality ratings. Journal of Research in Personality 2010;44:374-379.

52. Ladd, DR. Intonational phonology. Oxford: Oxford University Press; 2008. 
Advancing research and practice in entrepreneur-ship through speech analysis - from descriptive rhetorical terms to phonetically informed acoustic charisma metrics

53. Lucas K, Kerrick SA, Haugen J, Crider CJ. Communicating Entrepreneurial Passion: Personal Passion vs. Perceived Passion in Venture Pitches. IEEE Trans. Prof. Communication 2016;59:363378.

54. Malmsten E, Portanger E, Drazin C. Boo hoo: $\$ 135$ million, 18 months . . a dot.com story from concept to catastrophe. London: Arrow/Random House; 2002.

55. Marlow S., McAdam M. Gender and entrepreneurship: Advancing debate and challenging myths; exploring the mystery of the under-performing female entrepreneur. International Journal of Entrepreneurial Behavior \& Research 2013;19:114-124.

56. Meyer J, Rowan B. Institutional Organizations: formal structure as myth and ceremony. American Journal of Sociology 1977;83:340-363.

57. Morey, S. Deliverly @ machines: Toward a rhetoric and decomposition of new media. PhD thesis, University of Florida, USA; 2010.

58. Niebuhr O. On the phonetics of intensifying emphasis in German. Phonetica 2010;67:170-198.

59. Niebuhr O, Brem A, Novák-Tót E. Prosodic constructions of charisma in business speeches - A contrastive acoustic analysis of Steve Jobs and Mark Zuckerberg. In: Proc. 8th International Conference of Speech Prosody, Boston, USA, 2016a. 1-3.

60. Niebuhr O, Voße J, and Brem, A. What makes a charismatic speaker? A computer-based acousticprosodic analysis of Steve Jobs tone of voice. Computers in Human Behavior 2016b;64:366-382.

61. Niebuhr O. Clear Speech - Mere Speech? How segmental and prosodic speech reduction shape the impression that speakers create on listeners. In: Proc. 18th Interspeech Conference, Stockholm, Sweden, 2017. 894-898.

62. Niebuhr O, Alm M, Schümchen N, Fischer K. Comparing visualization techniques for learning second language prosody: First results. International Journal of Learner Corpus Research 2017;3:120.

63. Novák-Tót E, Niebuhr O, Chen A. A gender bias in the acoustic-melodic features of charismatic speech? In: Proc. 18th Interspeech Conference, Stockholm, Sweden, 2017. 2248-2252.

64. Niebuhr, O. The Kiel Intonation Model - KIM. In: J Barnes and S Shattuck-Hufnagel, editors. Prosodic Theory and Practice. Cambridge: MIT Press, to appear.

65. Parhankangas A, Ehrlich M. How entrepreneurs seduce business angels: An impression management approach. Journal of Business Venturing 2014;29:543-564.

66. Paroutis, S., Heracleous, L., Angwin, D. Practicing Strategy - Text and Cases (2nd ed.). Los Angeles: SAGE, 2016.

67. Perrotin O, D’Alessandro C. Target acquisition vs. expressive motion: Dynamic pitch warping for intonation correction. ACM Transactions on Computer-Human Interaction 2016;23:17.

68. Pentland A. Honest Signals - How they shape our world. Cambridge: MIT Press; 2008.

69. Peters J, Hoetjes M. The effect of gesture on persuasive speech. In: Proc. 18th Interspeech Conference, Stockholm, Sweden, 2017. 659-663.

70. Peters B. Form und Funktion prosodischer Grenzen im Gespräch. PhD thesis, Kiel University, Germany; 2006.

71. Pierrehumbert JB. The phonology and phonetics of English intonation. $\mathrm{PhD}$ thesis, MIT, Boston, USA; 1980.

72. Plutchik R. The emotions. Lanham: University Press of America; 1991.

73. Portes C, Beyssade C. Is intonational meaning compositional? Verbum 2012;XXXIV:1-27.

74. Prieto P. Intonational Meaning. WIREs Cogn Sci 2015;6:371-381.

75. Rodero E. Effectiveness, attention, and recall of human and artificial voices in an advertising

76. story Prosody influence and functions of voices. Computers in Human Behavior 2017.

77. Rosenberg A., \& Hirschberg J. Acoustic/Prosodic and lexical correlates of charismatic speech. In: Proc. Eurospeech 2005, Lisbon, Portugal, 2005. 1-4.

78. Rosenberg A, Hirschberg J. Charisma perception from text and speech. Speech Communication 2009;51:640-655.

79. Scherer, KR. What are emotions? And how can they be measured? Social Science Information 2005;44:695-729.

80. Scherer S, Layher G, Kane J, Neumann H, Campbell N. An audiovisual political speech analysis incorporating eye-tracking and perception data. In: Proc. Language Resources and Evaluation Conference (LREC), Istanbul, Turkey, 2012. 1114-1120.

81. Schuller B, Steidl S, Batliner A, Noth E, Vinciarelli A, Burkhardt F, van Son R, Weninger F, Eyben F, Bocklet T, Mohammadi G, Weiss B. A Survey on Perceived Speaker Traits: Personality, Likability, Pathology, and the First Challenge. Computer Speech and Language, Special Issue on Next Generation Computational Paralinguistics 2015;29:100-131. 
82. Sørensen, LS. How to Grow an Apple: Did Steve Jobs Speak Apple to Success? - An analysis of Steve Jobs's rhetorical and linguistic development in relation to Apple's organizational performance. MA thesis, Aarlborg University, Denmark; 2013.

83. Starr RL. Sweet voice: The role of voice quality in a Japanese feminine style. Language in Society 2015;44:1-34.

84. Streletzki JG, Schulte R. Which venture capital selection criteria distinguish high-flyer investments? Venture Capital 2013;15:29-52.

85. Stuart T, Huang H, Hybels R. Interorganizational endorsements and the performance of entrepreneurial ventures. Administrative Science Quarterly 1999;44:315-349.

86. Sudhoff S, Lenertova D, Meyer R, Pappert S, Augurzky P, Mleinek I, Richter N, Schließer, J, editors. Methods in Empirical Prosody Research. Berlin: de Gruyter; 2006.

87. Touati P. Prosodic aspects of political rhetoric. In: Proc. ESCA Workshop on Prosody, Lund, Sweden, 1993. 168-171.

88. Towler AJ. Effects of charismatic influence training on attitudes, behavior, and performance. Personnel Psychology 2003;56:363-381.

89. Tsai WC, Lai YC. Persuasion Methods of Fund Raising for New Ventures. In: Proc. PICMET 11 Technology management in the energy-smart world (PICMET), Portland, USA, 2011. 1-9

90. van Heuven VJ. Introducing Prosodic Phonetics. In. D Ode and C dan Vincent, editors. Experimental Studies of Indonesian Prosody. Leiden: Rijksuniversiteit te Leiden, 1994. 1-26.

91. van Stel A, Carree M, and Thurik R. The Effect of Entrepreneurial Activity on National Economic Growth. Small Business Economics 2005;24:311-321.

92. Verčič AT, Verčič D. Generic charisma - Conceptualization and measurement. Public Relations Review 2011;37:12-19.

93. Weber M. The Theory of Social and Economic Organization. New York: Free Press; 1947.

94. Zacharakis AL, Shepherd DA. The nature of information and overconfidence on venture capitalists' decision making. Journal of Business Venturing 2001;16:311-332. 